\title{
Remoulded Strength of High Plasticity Marine Silt Retrieved from Maintenance Dredging
}

\author{
Chee-Ming Chan $^{1} \&$ Mohd Nazri Mohd Yusof ${ }^{2}$ \\ ${ }^{1}$ Faculty of Engineering Technology, Universiti Tun Hussein Onn Malaysia, Batu Pahat, Johor, Malaysia \\ ${ }^{2}$ Faculty of Civil and Environmental Engineering, Universiti Tun Hussein Onn Malaysia, Batu Pahat, Johor, \\ Malaysia \\ Correspondence: Chee-Ming Chan, Faculty of Engineering Technology, Universiti Tun Hussein Onn Malaysia, \\ 86400, Batu Pahat, Johor, Malaysia. E-mail: chan@uthm.edu.my
}

Received: December 9, 2014 Accepted: December 15, $2014 \quad$ Online Published: February 2, 2015

doi:10.5539/mas.v9n6p13 URL: http://dx.doi.org/10.5539/mas.v9n6p13

\begin{abstract}
Maintenance dredging of marine waterways is necessary to ensure the efficiency and safety of the vessels navigating into the shallow waters. The dislodged sediments, commonly known as dredged soils are generally disposed of as a geo-waste. From the geotechnical point of view, the soil, mainly fine-grained particles like silt and clay, is too poorly for engineering applications. However, with suitable handling and treatment, it can be potentially reused as any sound geo-materials. Two feasible yet economical options for improving the remoulded strength of the soft material are as follows: (1) to partially pre-drain the soil in a backfill to improve the plasticity, and (2) to lightly solidify the soil with small dosages of binder, like cement. The present study examines the remoulded strength of high plasticity silt retrieved from a dredged site. The fine-grained soil was originally found to be in liquefied form (water content is 1.75 times the soil's liquid limit) with negligible shear strength or resistance. The material was semi-dried to form $60 \mathrm{~mm}$ thick soil beds at $0.90,1.25$ and 1.76 times the liquid limit. A separate set of soil beds (water content $=1.25$ times the liquid limit) were also prepared to determine the efficacy of light solidification in the remoulded strength, i.e. with 1,3 and $5 \%$ cement addition in the soil. The fall cone and vane shear tests were next carried out for each soil bed at predetermined intervals up to a week. The strength gain over time was recorded as reduction in the cone penetration and corresponding increase in the shear strength measurements. Overall the remoulded soil was found to gain strength with time without further drainage, due to the thixotropic mechanism of particles rearrangement. Besides, light solidification resulted in markedly improved strength of the remoulded material with less time required. In short, strength lost due to remoulding of the soil could be recovered with either methods, though time would be the determining factor in the choice made. It is concluded that dredged marine silt is reusable with carefully designed backfill procedure to allow for strength recovery, i.e. adequate rest period after pre-drainage, as well as the accelerated approach via light solidification.
\end{abstract}

Keywords: solidification, thixotropic hardening, dredged marine silt, shear strength, fall cone test

\section{Introduction}

Dredge marine sediments are a waste materials resulting from dredging, such as those carried out for maintenance in coastal areas. The dredging process involves dislodging and removing the sediments to ensure sufficient water depths provide safe passage for shipping route, and to keep access channels, fishing port basins and canals subject to high sedimentation open to safe navigation at all times (Sciortino, 2010). The dredged marine sediments are usually of poor geotechnical properties, with high water content, low strength and excessive compressibility, making it unfavourable as a geomaterial for civil engineering applications. This leads to the necessary disposal of the material in various dump sites or confined disposal facilities, both onland and offshore. Understandably, the transportation and disposal management of the material with high probability of contamination incur additional costs and efforts, at the risks of short and long term environmental impact.

It is therefore desirable to channel the dredged materials to a second life, though with certain pre-treatment for improving the originally poor geotechnical qualities. Indeed, a potentially effective approach is the solidification method, where small dosages of hydraulic binders are admixed with the soil to enhance the load-bearing performance (Chan et al., 2013). Reports have also been made of dredged marine sediments being recycled to 
produce other construction material, such as light-weight aggregates (Wang et al., 2008) and other road construction materials (Abriak et al., 2004). Besides, Syamsidik (2003) and Zhang et al. (2013) explored the possibility of reusing the material for backfilling in reclamation works. Kar et al. (2012) admixed natural coir and polypropylene with marine clay to improve the soil's compressibility, while Zubir et al. (2013) experimented with various pozzolana additions to dredged sludge from a dam. Attempts have also been reported of innovative foundation systems tailor-made for such soft deposits (Chan et al., 2010). All the above measures essentially recycle the otherwise material, simultaneously contributing to the conservation of the environment by reducing waste disposal, whether onland or offshore.

When placed in a backfill for reclamation works, one of the key factors to be considered for the design is the time-dependent strength recovery of the soil. Taken into account the high water saturatation of the dredged marine soil, the soil would tend to undergo continuous excessive subsidence under its own weight alone for a long period, leading to possible structural damage to the development over the reclaimed land. However, with suitably controlled water content, and given adequate rest period, the dredged marine soil would self-consolidate with time to form a stronger and stiffer soil bed for load-bearing. This is explained by a time-dependent phenomenon known as thixotropic hardening (Seng and Tanaka, 2012). Thixotropic hardening occurs when a remoulded and destructured soil, such as the removed sediments, is allowed a certain rest period to regain its strength and stiffness (Takeda et al., 2012). The rearrangement of the soil particles and closing of the voids within the soil mass help rebuild the structural matrix of the material, giving it skeletal resistance against any imposed load. The process depends on the properties of the materials and involves structural changes of the soil (Perret et al., 1996). During the hardening process, no more water is expelled from the soil, hence the volume reduction, albeit small, is entirely due to reorganization of the soil particles into a denser and stronger mass.

The present study examined a marine silt sample retrieved from a maintenance dredged site. As silt is technically very fine sand, the material was expected to undergo excess pore water dissipation at a higher rate than the more finely grained clay soil. Several soil beds were prepared from the remoulded dredged marine silt at different initial water contents, where laboratory vane shear and fall cone tests were conducted at predetermined intervals up to a week. The rather short test period was considered acceptable as the the uniform soil bed thickness was no more than $60 \mathrm{~mm}$, hence limiting significant thixotropic hardening effect to a shorter period. A separate set of soil beds was also prepared with small cement dosage additions to determine the possible accelerated rate of strength recovery

\section{Method}

\subsection{Dredged Marine Silt}

The dredged marine silt examined in the present study was collected from a maintenance dredged site on the east coast of Peninsular Malaysia (Figure 1). Physical properties of the soils are given in Table 1. Note that the natural water content was about $55 \%$ of the Liquid Limit (LL), way above the water content where the soil starts behaving like a liquid (i.e. flowable). This explains the physical condition of the dredged material, which was saturated with water, soft and weak with negligible load-bearing capacity. The soil sample was first semi-dried over a heated pan to reduce the initially very high water content (Head, 2006). Next water content of the soil was carefully adjusted with the addition of deinoised water, so that the remoulded soil contained a known amount of water for subsequent tests, i.e. 0.90, 1.25 and 1.76 times the LL. Mixing was carried out in a conventional kitchen mixer at moderate speed for approximately 10 minutes. This was to ensure uniformity of the remoulded sample.

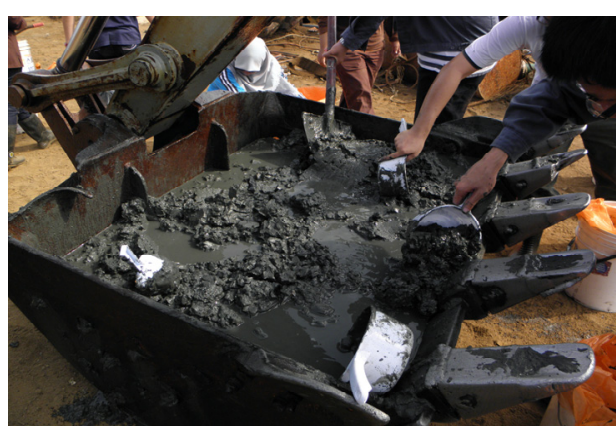

Figure 1. Dredged samples collected from the bucket of a backhoe dredger

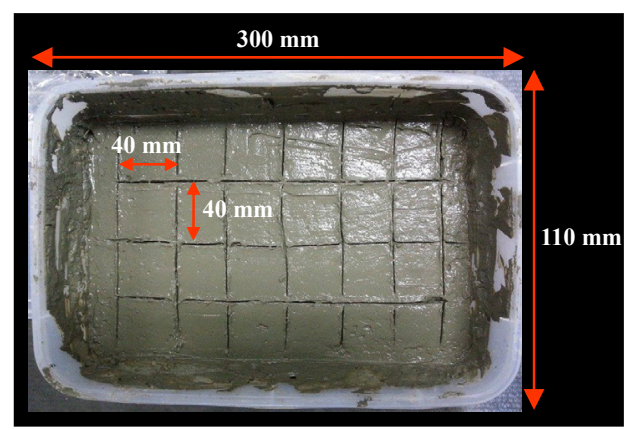

Figure 2. Test soil bed 
A separate set of samples were prepared at $1.25 \mathrm{LL}$ with the addition of small quantities of dry Ordinary Portland Cement powder (i.e. 1, 3 and $5 \%$ per dry weight of the soil), for the purpose of exploring possibilities of shortening the rest period required for strength recovery of the remoulded soil. The cement dosages were intentionally kept low to avoid over-treating the soil, resulting in an excessively hard and stiff soil bed. As the purpose of solidification is to improve the soil's load-bearing capacity and not to overly strengthen or stiffen it, excessive cementation would be both wasteful and cunter-productive.

The remoulded soil was next placed in moulds of $300 \mathrm{~mm}$ x $110 \mathrm{~mm}$ x $130 \mathrm{~mm}$ by layers and lightly tapped to remove any entrapped air. All soil beds were prepared to $60 \mathrm{~mm}$ thick for measurements with the fall cone and vane shear devices. The surface of the soil bed was marked out with equally spaced grid lines to indicate measurement points for the respective tests (Figure 2). As the fall cone test was performed in parallel with the vane shear test, the points of measurement in the soil bed were spaced at $40 \mathrm{~mm}$ from one another to avoid disturbance of the surrounding soil.

Table 1. Properties of dredged marine silt sample

\begin{tabular}{cc}
\hline Soil type & High plasticity silt $(\mathrm{MH})$ \\
\hline Water content $(\mathrm{w})$ & $126.49 \%$ \\
Liquid Limit $(\mathrm{LL})$ & $72.00 \%$ \\
Plastic Limit $(\mathrm{PL})$ & $39.42 \%$ \\
Plasticity Index $(\mathrm{PI})$ & 32.58 \\
Spesific Gravity $\left(\mathrm{G}_{\mathrm{s}}\right)$ & 2.33 \\
pH & 8.60 \\
\hline
\end{tabular}

\subsection{Fall Cone Test (FST)}

The fall cone test is conventionally used to determine the Liquid Limit of soils, where the cone penetration depth is related with the shearing resistance of the soil at different water contents (BS1377, 1990). Historically Hansbo (1957) showed that the simple and quick test can also be referred to in gauging soil's undrained shear strength. In the present study, the fall cone test was adopted to monitor the changes in shear resistance of the remoulded soil bed with time. The test was conducted by dropping an $80 \mathrm{~g}$ cone, with apex angle of $30^{\circ}$, from the surface of the soil sample and leaving it to penetrate the soil under its self-weight for 5 seconds. The penetration depth for the soil was then measured and recorded.

\subsection{Vane Shear Test (VST)}

The laboratory vane shear test was conducted to monitor the increase in shear strength by thixotropic hardening, with or without induced solidification. The test was considered the most appropriate since the soils were classified as cohesive soil of fine grained type with very low strength, where other strength tests, such as unconfined compression test, would be impractical. A standard $12.7 \mathrm{~mm} \times 12.7 \mathrm{~mm}$ vane was used with corresponding torsion springs for the measurements. Selection of the torsion spring was based on the expected maximum stress exerted by the soil against the vane during the shearing process. The shearing mechanism via the spring's torsion was effected by rotation of the vane at $10^{\circ}$ per minute. The undrained shear strength $\left(\mathrm{c}_{\mathrm{u}}\right)$ is derived from the vane shear test by Eq. (1):

$$
c_{u}=2 T / \pi D^{2}[H+(D / 3)]
$$

where $\mathrm{M}=$ torque applied $(\mathrm{Nmm}), \mathrm{K}=$ torsion spring constant $(\mathrm{Nmm}), \mathrm{D}=$ overall width of the vane $(\mathrm{mm})$ and $\mathrm{H}=$ the length of the vane $(\mathrm{mm})$.

\section{Results}

\subsection{Soil Drying}

Results from the heat drying of the soil to remove excess water content initially are shown in Figure 3 . Temperature of the soil was found to hover between $80-105^{\circ} \mathrm{C}$, while the water content was reduced by $72 \%$ in 30 minutes. This is attributed to evaporation which was quickened by the heated pan. 


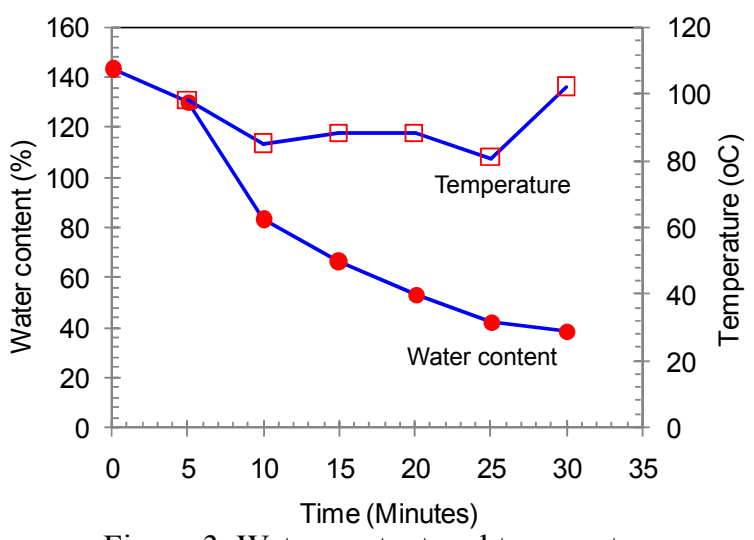

Figure 3. Water content and temperature during soil drying process

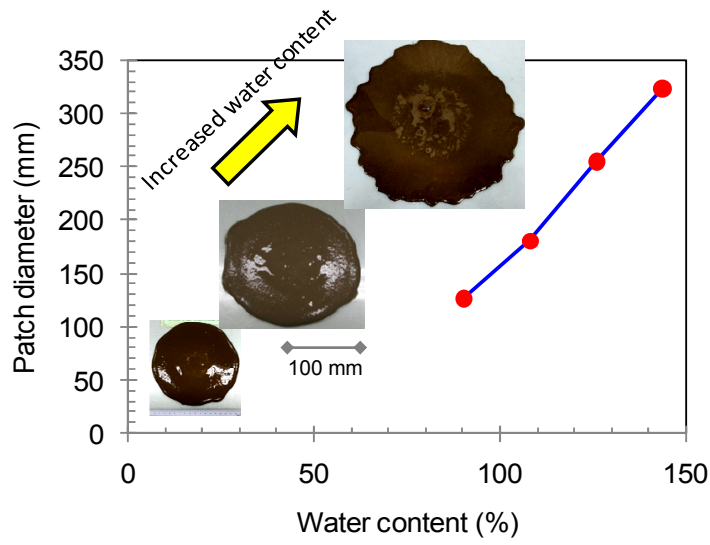

Figure 4. Flowability test results

Water content reduction was observed to be rather dramatic in the first 10 minutes, after which the reduction rate was almost constant at $2.6^{\circ} \mathrm{C}$ per minute.

The soil drying procedure was not intended to fully dehydrate the soil, but to partially remove the excess water for subsequent preparation of the remoulded soil beds at known water contents. Without this procedure, inconsistencies of the soil beds could lead to unreliable measurements of the strength recovery with time.

Liquidity of the remoulded soil at different water contents was gauged by a simple flowability test. A $38 \mathrm{~mm}$ diameter and $76 \mathrm{~mm}$ high plastic tube was first filled with the soil sample. The tube was then slowly lifted to allow the soil to flow out by its own weight. The diameter of the patch made by the flowable soil was measured and plotted against the soil's water content in Figure 4. The water contents shown in the plot corresponded with 1.25. 1.50. 1.75 and 2.00 times the Liquid Limit of the soil. As Liquid Limit is indeed the water content unique to each soil, at which the soil begins to flow like a liquid, these remoulded mixtures were in excess of pore water and readily flowed with gravity.

The pictures taken of the patches are also included as insets in the same figure. Apparently the patch diameter increased almost linearly with higher water content, indicating greater flowability of the soil. The soil's structure was weakened with increased water content to a state were it starts to 'flow' under its own weight. Further addition of water simply induced segregation of the soil particles in a liquefied matrix, i.e. gradual loss of shear strength of the soil as mobilized by frictional interaction between the particles. These observations are useful in anticipating the ease of placing the soil bed, as well as the ease of mixing with cement in preparing the lightly solidified samples. Better uniformity can be expected of the more flowable soil, though excessive water content can also be a cause for bleeding of the sample and an impedence to effective solidification.

\subsection{Cone Penetration}
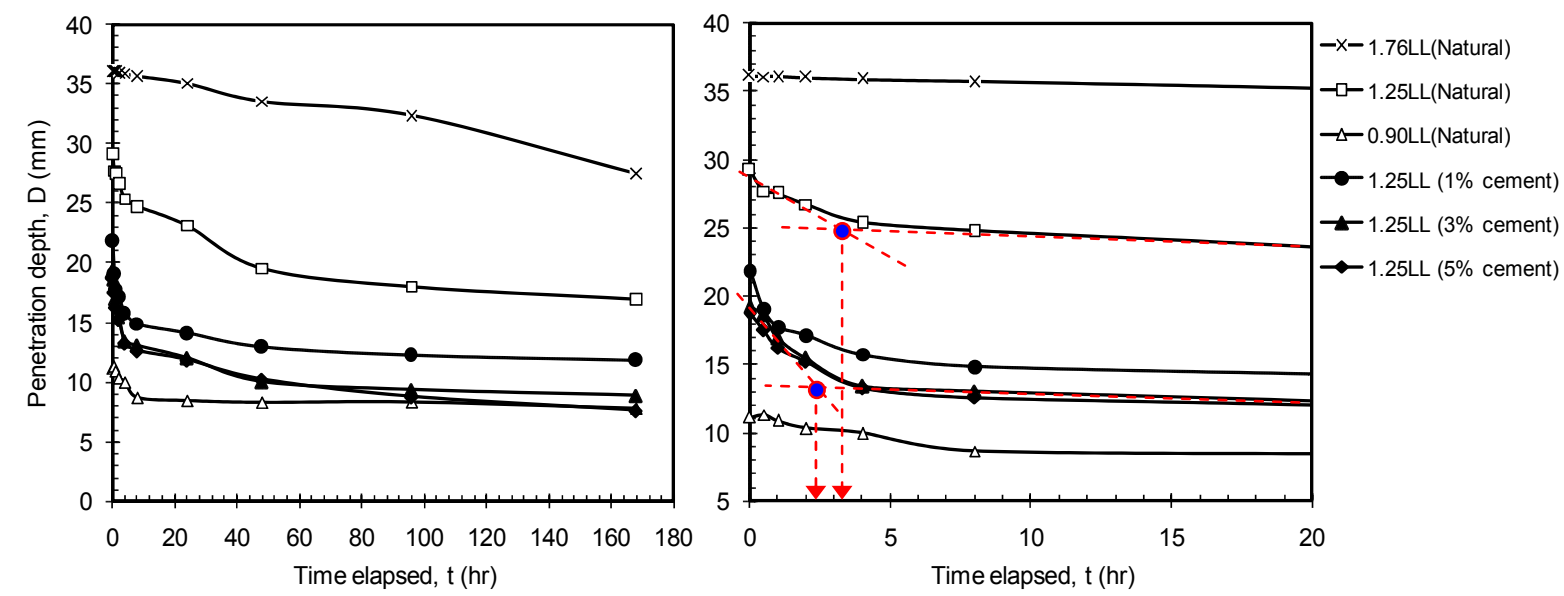

Figure 5. Cone penetration depth, D - time elapsed, t plots (enlarged on the right) 
Figure 5 shows the cone penetration depth (D) plotted against the time elapsed, as measured using the fall cone apparatus at predetermined intervals. Note that the figure on the right is an enlargement of the same plots within the initial 20 hours of remoulding. Apparently higher initial water contents corresponded with more significant cone penetration, indicating less strength recovery of the soil with time. This was consistent throughout the measurement period of 168 hours (i.e. 7 days), where the reduction of $\mathrm{D}$ values was found no more than 1.76 times the cone penetration depth at time zero. Overall, the $30 \%$ difference between the soil's initial water content resulted in final reduction of the cone penetration by ratios of 1.6 to 2.2, with the drier samples recording more significant remoulded strength recovery despite the same water content difference.

The lightly solidified samples with initial 1.25LL and addition of 1-3 \% cement clearly sustained less disturbance from the cone drop. The reduced penetration depth was observed to be consistent throughout the test period, though the more cement in the soil did contribute to the increased penetration resistance of the cone. Interestingly addition of 3 and $5 \%$ cement made little difference in the remoulded strength recovery of the soil. In fact both soil beds seemed to converge in terms of the 168-day cone penetration measurement with sample 0.90LL. This suggests the benefits of pre-drying the dredged soil, or forced dissipation of the initially high water content of the soil in prompting greater strength gain within a shorter time. Nonetheless the same effect could be achieved by admixing the soil with small quantities of cement, such as 3-5\%. The change in penetration rate of the cone can be seen more clearly in the enlarged plots on the right of Figure 5. Apart from sample 1.76LL with excessive water content, all other samples showed discernible deflection points between the intial and subsequent cone penetration depths. For instance, sample 1.25LL and its solidified counterpart, $1.25 \mathrm{LL}$ (3\% cement). The change in gradient of the plots took place approximately 1 hour apart, as cement effectively strengthened the originally destructured soil within a shorter period.

Besides it is noted that the cone penetration resistance remained largely unchanged beyond the deflection point, an indicator of the gradually stabilizing soil's structure with less dramatic particles rearrangement.

\subsection{Undrained Shear Strength}
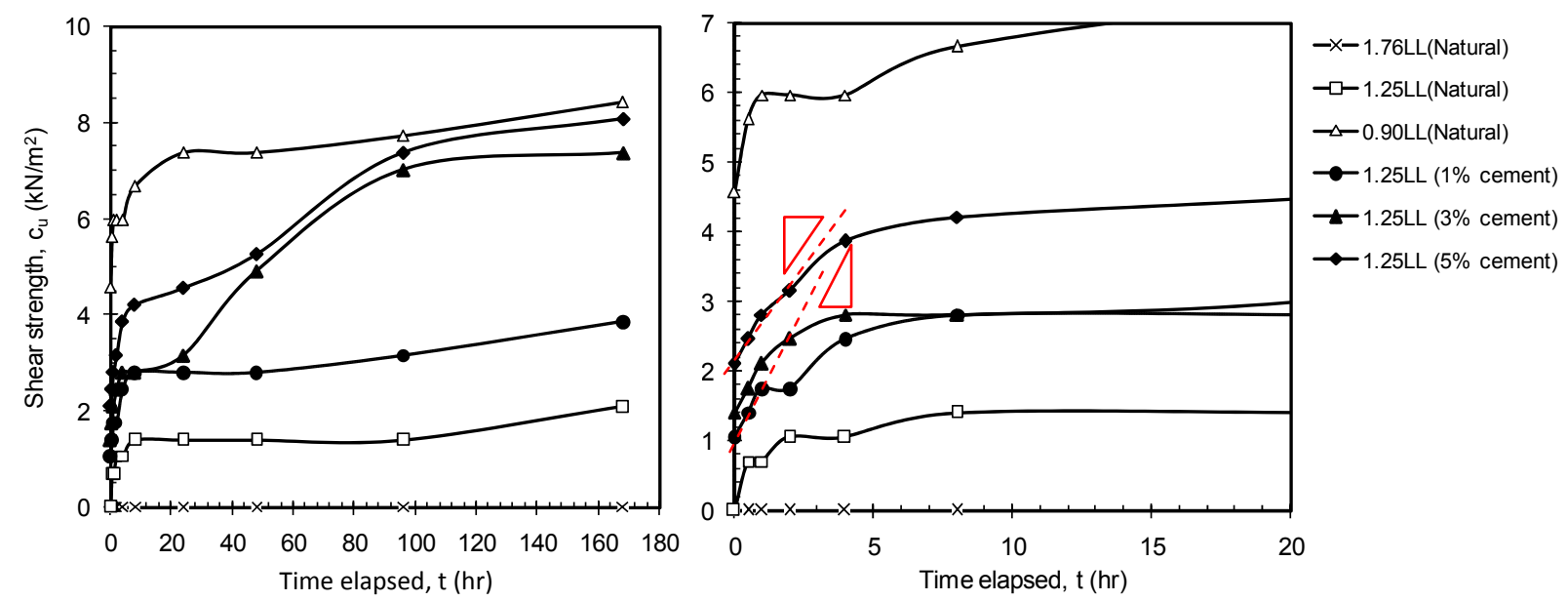

Figure 6. Undrained shear strength, $c_{u}-$ time elapsed, t plots (enlarged on the right)

The undrained shear strength $\left(c_{u}\right)$ monitored throughout the 7-day period is shown in Figure 7. Similarly, the enlarged plots are included on the right side of the figure. In general the strength data is in good agreement with the cone penetration record. However the softest sample, 1.76LL, was not measurable with the laboratory vane shear test, as represented by the data points lying along the $\mathrm{x}$-axis. Less initial water content in the soil enabled greater improvement of the remolded strength, as well as greater rate of improvement with time. Cement addition contributed to the strength gain remarkably, but 3-5\% dosage was not found to produce much difference in the resulting strength. Also, the final strength recorded for these lightly solidified samples were very close to that of $0.90 \mathrm{LL}$. This relates well with the fall cone test data, where the cone penetration magnitude and rate had an inversed correlation with the strength recovery of the remoulded soil (Figure 6).

The enlarged plots on the right indicated marked initial strength gain, especially for the lightly solidified samples. While the final strength attained by the samples with 3 and $5 \%$ cement addition were similar, the higher cement dosage in sample 1.25LL $(5 \% \mathrm{C})$ induced greater strength gain in the soil, as indicated by the gradient difference in Figure 7. As for the unsolidified samples, 0.90LL underwent more significant strength recovery compared to $1.25 \mathrm{LL}$, both in terms of magnitude and rate. Overall, the remoulded strength of the dredged marine silt, 
regardless of the initial water content and solidified conditions, showed potential for continuous increment with time. This is despite the fact that the all samples (besides sample 1.76LL) demonstrated similar strength gain rate after the marked rise at the initial stage. It is therefore suggestive that the the light solidification due to addition of small cement dosages altered the soil's original fabric mildly. Nonetheless the ultimate strength magnitude is dependent on the water content and cement dosage, where the material's inherent structure was either stiffened with time or induced solidification. To what extent can this structure be retained upon loading, and the deformation characteristics of the material with load would require further examination to determine.

\subsection{Penetration-Strength Correlation}

The correlation between $\mathrm{c}_{\mathrm{u}}$ and $\mathrm{D}$ is shown in Figure 7, where the 2 parameters are best related with a power law regression with coefficient of correlation, $\mathrm{R}^{2}=0.916$. The plot suggests negligible effect the small cement dosages had on the strength and cone penetration measurements, as indicated by the close alignment of the data along the regression line. Although the vane shear test was incapable to gauge the remoulded soil's strength, the fall cone test did capture shear resistance in the soil against the falling cone. Referring to the figure, these very loe strength corresponds with $\mathrm{D}$ in the range above $30 \mathrm{~mm}$. The $\mathrm{c}_{\mathrm{u}}-\mathrm{D}$ correlation also appeared to be distinguishable by 2 parts with the boundary at approximately $\mathrm{D}=15 \mathrm{~mm}$. It follows that $\mathrm{c}_{\mathrm{u}}$ in the range of 3-8 $\mathrm{kPa}$ tallies with $\mathrm{D}=8-15 \mathrm{~mm}, \mathrm{c}_{\mathrm{u}}=1.5-3 \mathrm{kPa}$ corresponds with $\mathrm{D}=15-20 \mathrm{~mm}$ and $\mathrm{c}_{\mathrm{u}} \leq 1.5 \mathrm{kPa}$ records $\mathrm{D}$ above $20 \mathrm{~mm}$. The greater the strength of the soil, the greater the resistance against the shearing of the cone, hence the less penetration was registered from the cone drop. At lower strength range, the cone penetration depth became less discernible, as the shearing momentum due to self weight of the cone overwhelmed the minute shear resistance of the weak soil.

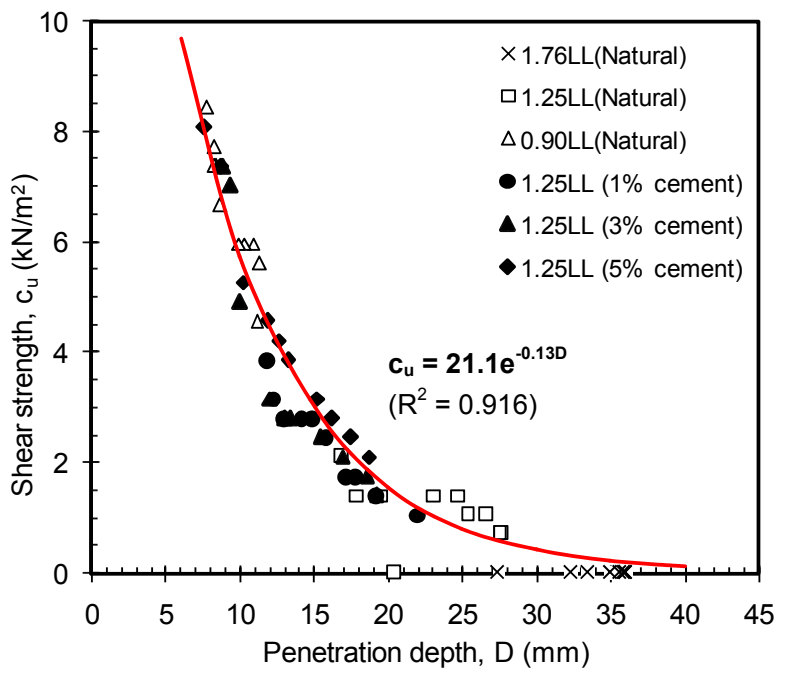

Figure 7. $c_{u}-D$ correlation

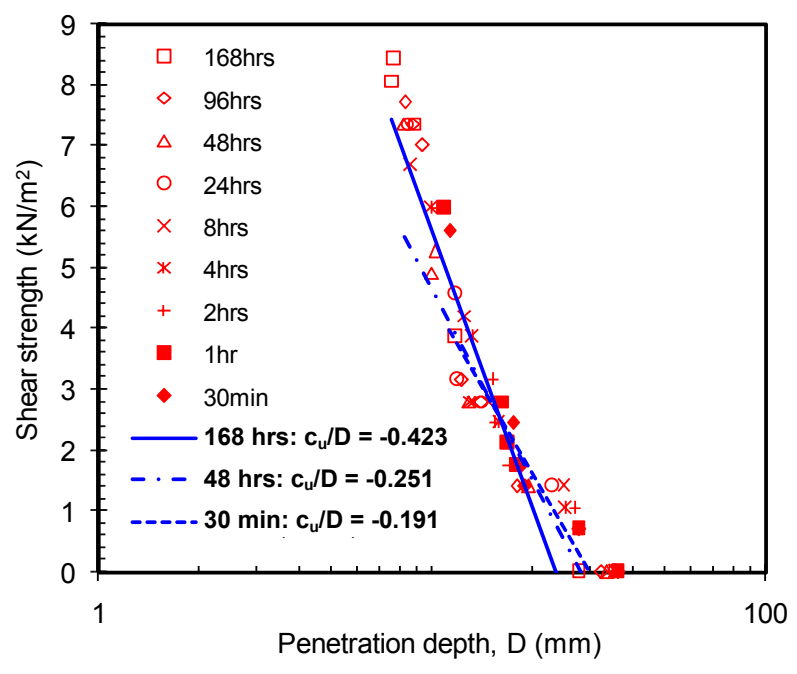

Figure 8. Change of $\mathrm{c}_{\mathrm{u}}$-D with time

Figure 8 replotted the $\mathrm{c}_{\mathrm{u}}$-D data grouped according to the time interval against a log-scale $\mathrm{x}$-axis. It may appear that the data share the same regression line as in Figure 7 but when individual best fit lines are plotted, the difference in gradient becomes apparent. For illustration purposes, the regression lines for $168 \mathrm{hrs}, 48 \mathrm{hrs}$ and 30 $\mathrm{min}$ are included in the figure. Note the increasing gradient with time, i.e. $\mathrm{c}_{\mathrm{u}} / \mathrm{D}: 168 \mathrm{hrs}>48 \mathrm{hrs}>30 \mathrm{~min}$. This is in accordance with earlier discussion about the more significant strength gain with time. It therefore concurs that the remoulded strength of the dredged marine silt could be effectively improved with time or light solidification. The fact that the data lies relatively close to the regression lines also suggests the mild effect small quantities of cement had on the soil's orginal properties.

\section{Conclusions}

A series of cone penetration and vane shear tests were conducted on a dredged marine silt sample prepared at different water contents, with or without light solidification with cement. The main purpose of the study was to acertain the remoulded strength of the disturbed material with time as well as with induced cementation. The main findings of the are summarized as follows:

- The addition of small quantites of cement (i.e. 1-5 \%) was expedient in improving the remoulded strength of the high plasticity dredged marine silt placed as a backfill. 
- $\quad$ The time required for the soil to ragain strength could be effectively reduced by either semi-drying cum pre-draining the soil, or by admixing small dosages of binders like cement with the soil.

- An exponential correlation could be used to estimate the undrained shear strength $\left(\mathrm{c}_{\mathrm{u}}\right)$ of the remoulded soil, which showed no apparent distinction between the natural and lightly solidified materials.

- $\quad$ The $c_{u} / D$ ratio showed a subtle increase with time, in keeping with strength recovery of the remoulded soil as structure was regained while the soil was left to rest.

In a nutshell, the findings above are elementary in the design of of backfills and reclaimation works involving high plasticity dredged marine silt, i.e. the remoulded strength - time relationship, which were determined using the conventional laboratory fall cone and vane shear apparatus.

\section{Acknowledgments}

The work described in the paper was part of research project funded by FRGS 1436 by Ministry of Education, Malaysia. Appreciation is also due to the technical staff who assisted in the laboratory work involved.

\section{References}

Abriak, N. E., Damidot, E., Zentar, R., \& Wang, D. (2004). Characterization of dredged marine sediments for road construction. Douai, France.

British Standard Institution. (1990). British Standard 1377 (BS1377): Methods of test for soils for civil engineering purposes, Part 2: Classification tests. London: BSI.

Chan, C-M., Pun, K. H., \& Ahmad, F. (2013). A Fundamental parametric study on the solidification of Malaysian dredged marine sediments. World Applied Science Journal, 24(6), 784-793.

Chan, C. M., Wong, P. Y., \& Lee, C. C. (2010). Subsidence control of construction on soft soils with 'Akar Foundation'. Modern Applied Science, 4(8), 12-23. http://dx.doi.org/10.5539/mas.v4n8p12

Hansbo, S. (1957). A new approach to the determination of the shear strength of clay by fall cone test. International Proceeding, Royal Swedish Geotechnical Society, 1-48.

Head, K. H. (2006). Manual on soil laboratory testing (3rd ed.). United Kingdom, UK: Whittles Publishing.

Kar, R. K., Pradhan, P. K., \& Naik, A. (2012). Consolidation characteristics of fibre-reinforced cohesive soil. Electronic Journal of Geotechnical Engineering, 17, 3861-3874.

Perret, D., Locat, J., \& Martignoni, P. (1996). Thixotropic behaviour during shear of a fined-grained soil mud from Eastern Canada. Engineering Geology, 43, 31-44. http://dx.doi.org/10.1016/0013-7952(96)00031-2

Sciortino, J. A. (2010). Fishing harbur planning, construction and management. FAQ Fisheries and Acuaculture Technical Paper, 539, 337.

Seng, S., \& Tanaka, H. (2012). Properties of very soft clays: A study of Thixotropic hardening and behavior under low consolidation pressure. Hokkaido University, Japan.

Syamsidik. (2003). Singapore coastal reclamation: History and problems. Academic Seminar of Indonesian Students Association (PPI), University Sains Malaysia.

Takeda, T., Sugiyama, M., Akaishi, M., \& Chang, H. W. (2012). Secondary compression behaviour in One-dimensional consolidation tests. Journal of GeoEngineering, 7(2), 53-58.

Wang, H. P., Wei, Y. L., Yang, J. C., Lin, Y. Y., \& Chuang, S.Y. (2008). Recycling of harbour sediment as lightweight aggregate. Marine Pollution Bulletin, 867-872.

Zhang, R. J., Santoso, A. M., Tan, T. S., \& Phoon, K. K. (2013). Strength of high water content marine clay stabilized by low amount of cement. Journal of Geotechnical and Geoenvironmental Engineering, 139, 2170-2181. http://dx.doi.org/10.1061/(ASCE)GT.1943-5606.0000951

Zoubir, W., Harichane, K., \& Ghrici, M. (2013). Effect of lime and natural Pozzolona on dredged sludge engineering properties. Electronic Journal of Geotechnical Engineering, 18, 589-600.

\section{Copyrights}

Copyright for this article is retained by the author(s), with first publication rights granted to the journal.

This is an open-access article distributed under the terms and conditions of the Creative Commons Attribution license (http://creativecommons.org/licenses/by/3.0/). 